\title{
PSYCHE.
}

\section{INTRODUCTION TO BRAUER AND VON BERGENSTAMM'S VORARBEITEN ZU EINER MONOGRAPHIE DER MUSCARIA SCHIZOMETOPA.-I.}

\author{
BY C. H. TYLER TOWNSEND.
}

[The following translation of the introductory remarks and generalizations to be found in part $\mathrm{i}$ of Braner and $\mathrm{v}$. Bergenstamm's work on Tachinidae, etc., was sent me some time ago by Professor J. M. Aldrich, of Brookings, South Dakota. The translation was made in the rough by him, and at his suggestion I have revised it for publication. The original suggestion to publish it was my own. Its appearance in English will, I believe, be of advantage to American students, since a growing attention is now being directed to this family of Diptera in this country. The introduction contains many generalizations and valuable ideas not known outside of special workers in this family, and gives an insight into the methods of work employed by its authors, which is not devoid of interest even to those who may not accept in full the plan of their work as carried out.

I do not wish to be understood as sanctioning the views here exposed. The portion treating of head-characters, other characters, relationships, etc., which comprises nearly the whole and is merely descriptive, is excellent. I agree with the authors on what is said regarding the necessity of smaller groups (at least more restricted genera) in the Muscidae, but I do not sanction the extreme to which they have pursued this plan. Finally, I can not agree with what is said favoring the abandonment of generic names long in use.]

It is a fundamental principle in the development of the whole Dipterous stock that, from the lowest (Orthorrhapha nematocera) to the most differentiated or highest (Cyclorrapha schizometopa), the actual value of the genus, and of the systematic series generally, becomes less and less. This proposition seems applicable to all groups of animals, -in all cases the most recent forms are more closely related and more difficult to characterize than older ones. For example, this is the case in the land-snails, as compared with sea-snails and mussels. The cause lies in the numerous intermediate forms occurring in a group of animals which has just reached its period of greatest prolificness.

But in particular cases this statement may not be true, for there are indeed single branches of the older groups which have only at the present time reached the stage of multiform development. With this limitation, it is true 
that the related groups of the Orthorrapha, and even the Cyclorrapha of older origin, as the Syrphidae, are much more sharply separated from each other, and easier to establish by definite characters, than those of the Muscaria. The Muscaria schizometopa, which, exclusive of the Anthomyidae, are here treated, have been repeatedly divided into differently related groups, but no author has been able to establish his groups upon characters which apply to all cases. In the description of genera almost every one has overstepped, either inadvertently or purposely, the limits he had previously set. 'The characters applied change in their conbination with such complexity that it is almost impossible to discover one which continues constant through several or many genera, much less to discover a harmony of characters indicating a natural system. After having labored long in vain to define the previously formed groups by constant characters, we have come to the conclusion that our object can only be attained in another way,-by ignoring the previously established groups of Tachinaria, Dexiaria, \&c., and designating a much larger number of smaller groups, or related series. Within such a small group it is possible to determine harmoniously combined characters for a series of several genera. How these groups are to be arranged with reference to each other can, however, be settled only very impeifectly. We refer to this particularly, as it might otherwise be supposed that we wish in the sequence observed to indicate a serial relation. To us the relations seem rather to extend in many directions from every group, and to allow no simple linear arrangement.

The question may arise, why we do not rather combine all the forms of a group into one genus with many subgenera. On this question we take the ground occupied by almost all systematic writers at the present day. In the first place, it is more intelligible to fix our stations by names than by numbers; second, our genera, with few exceptions, show only plastic characters; third, we possess several species for almost every genus, which are distinguished from each other by many subordinate differences; and fourth, we would so treat the Muscaria, and so comprehend the value of genera, as to agree with what Rondani, the best reviser of the group, has already done. Whoever begins to divide the genera Tachina, Dexia, \&c., is compelled to continue the work until only those characters which are altogether subordinate remain for the species, - the arrangement of the macrochaetae, the form of the sexual organs of the male and female (not the typical development for a group, but lesser characters than these; for instance in Phaniidae), the color, hair, width of face, \&c.

If we adhere to the proposition that a genus comprises only a series of species, disunited from other series by a lack of connecting forms, then we must mark off a new genus whenever, among the slight subordinate differences of the various parts of the body, new characters are found, lacking in the previous 
series and therefore giving rise to a new combination. Such characters are then important, if they constantly recur in a series in combination with others.

Since a genus cannot be defined except as a natural series of related species, we refrain from entering into the distinction of subgenera, groups of species, etc. We find better stopping-places for the limitation of families, and on this point we maintain the view which was set forth in the Journal of the Imperial academy of sciences (v. 9r, i. I 895 , p. 327), according to which " the known larval forms furnish important characters for separation into the groups known among insects as families and genera", seldom for a higher category. The expression genus was there discarded, for two reasons: first, because many of our families are the genera of older authors, and second, because in genera in which the like or similar life habits of the larvae come into consideration among the characteristics, the larvae have acquired constant characters.

If in more recent times, strange to say, it is still disputed whether the classification should be based upon the mature insect or upon the entire development, we can quickly decide, since the former view is contrary to all the fundamental principles of the natural system. Whither views formed on such a basis lead, may be best seen in the new division of the Coleoptera into genuine and rhynchophorous. This comes from a misunderstanding of the value of characters derived from the earlier stages. The latter must, for the higher categories (family, order, class, etc.), be considered of high importance; for genera and species the characters of the imago are always more important, because the larvae (with few exceptions) show far fewer distinguishing features, and by means of them one could only distinguish series [not species]. Perfectly in harmony with this is the communication presented in the Records of the Imperial academy (math. nat. class, v. 47, p. $3^{6}$ ) on the socalled family of Muscaria schizometopa, where the non-existence of such a family was proved. The idea of many smaller groups was also suggested there. That the known larval forms cannot in this case prove the contrary, had been shown even earlier (Verh. k. k. zool.-bot. ges., I878, г6r. See also Loew, Stettin. ent. zeit., r845, p. 3 1 2).

In conclusion we note particularly that it shall be our special task to establish the most natural genera possible, and in every case to attempt to reduce former genera to this basis. Whoever thinks the genera too many is at liberty to consider them merely series of species, for convenience given a definite name. Some of our groups are then to be considered as genera, while others may be subdivided.

Since our characterization of the groups is based on essentially different points of structure from those of former authors, we are in a position to arrange in our system only those forms which we could examine and of which we possess the type specimens. Species, the descriptions of which do not mention the points that are important to us, must be laid 
aside for the present, because their false arrangement would only cause more confusion than already exists. Farther on in our work we will express our views on the forms which have not been examined by us. Meanwhile we recommend that the possessors of types examine them in the light of our system.

\section{JOHN WITT RANDALL.}

Dr. J. W. Randall who died at Roxbury, Mass., 25 January I 892 is known to the present generation of entomologists as the author of two papers descriptive of Coleoptera from Maine and Massachusetts published more than fifty years ago in the second volume of the Boston journal of natural history. John Witt Randall was born in Boston, I3 November I8I3. His father Dr. John Randall was an eminent physician of Boston and his mother Elizabeth Wells was the granddaughter of Samuel Adams the revolutionary patriot. $\mathrm{He}$ graduated from Harvard College in I 834. One of his classmates says: "he displityed a marked originality of character. Though among us, he was not wholly of us, but seemed to have thoughts, pursuits, and aspirations to which we were strangers. His tastes developed in a scientific direction, entomology being the branch to which he devoted himself. The college at that time did little to encourage such pursuits, but he pursued the even tenor of his way till he had made a very fine collection of insects." Dr. Randall studied medicine after his graduation. He was offered and accepted an appointment in zoology connected with the Wilkes exploring expedition to the South Seas; owing however to the de- lays which occurred before the expedition sailed he resigned.

Dr. Randall's scientific papers are as follows :

I. Descriptions of new species of coleopterous insects inhabiting the state of Maine. Bost. journ. nat. hist., Feb. I 838 , v. 2, no. I, pp. I-33.

2. Descriptions of new species of coleopterous insects inhabiting the state of Massachusetts. Bost. journ. nat. hist., Feb. I838, v. 2, no. 1, pp. 34-52.

(See Proc. Bost. soc. nat. hist., Jan. I 875 , v. I7, pp. $373-385$. On the species of Coleoptera described by Mr. J. W. Randall, by P. S. Sprague with notes by E. P. Austin.)

3. Catalogue of the Crustacea brought by Thomas Nuttall and J. K. Townsend from the west coast of North America and the Sandwich Islands with descriptions of such species as are apparently new, among which are included several species of different localities previously existing in the collection of the Academy. Journ. acad. nat. sci. Phil., I 839 , v. 8, pt. I, pp. го6-147, pl. 3-7.

A volume on the animals and plants of Maine was prepared but not published. His volume of poems entitled Consolations of Solitude, Boston, 1856, 2d edition 1857 , was commended by J. H. Abbott in the North American review. 

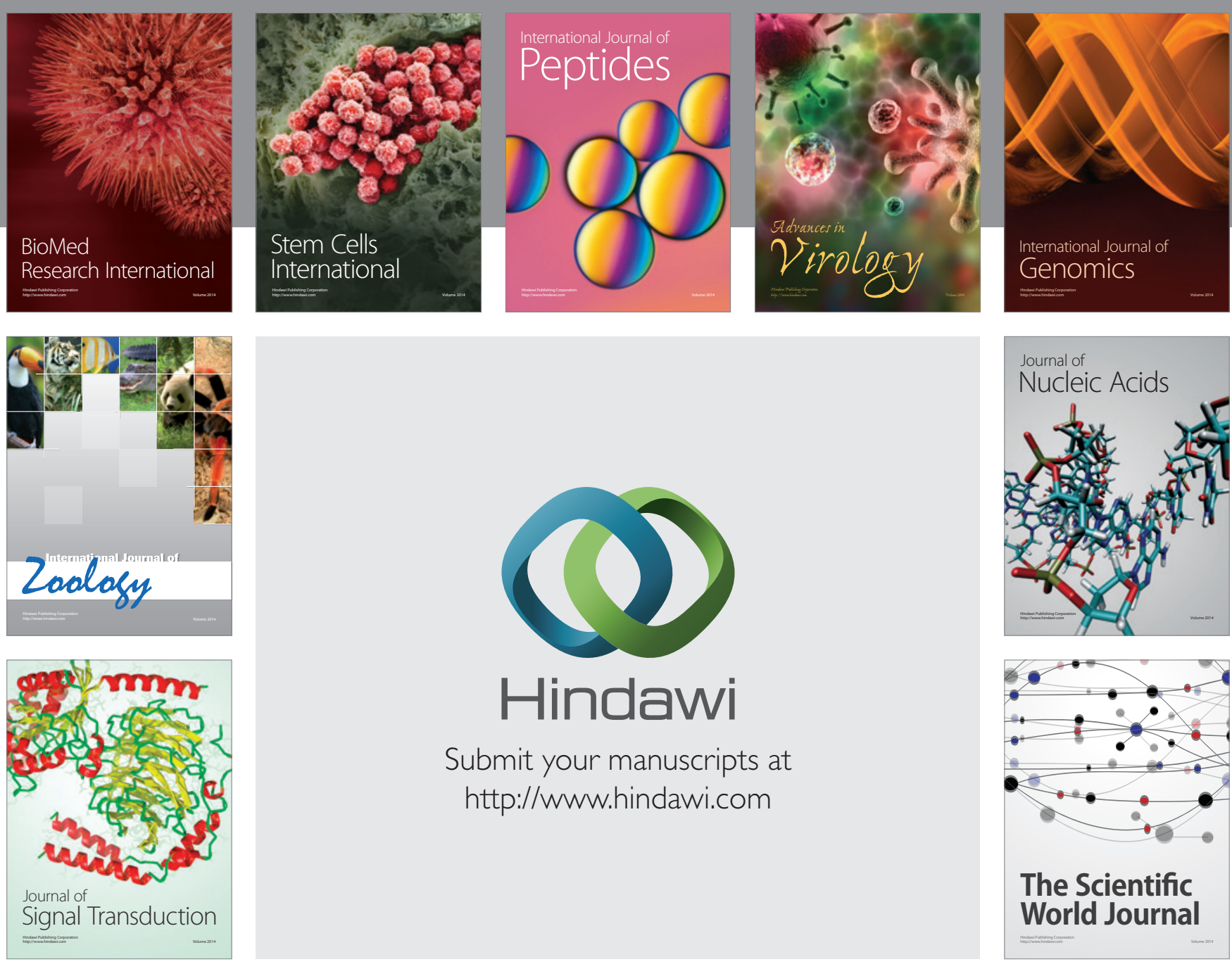

Submit your manuscripts at

http://www.hindawi.com
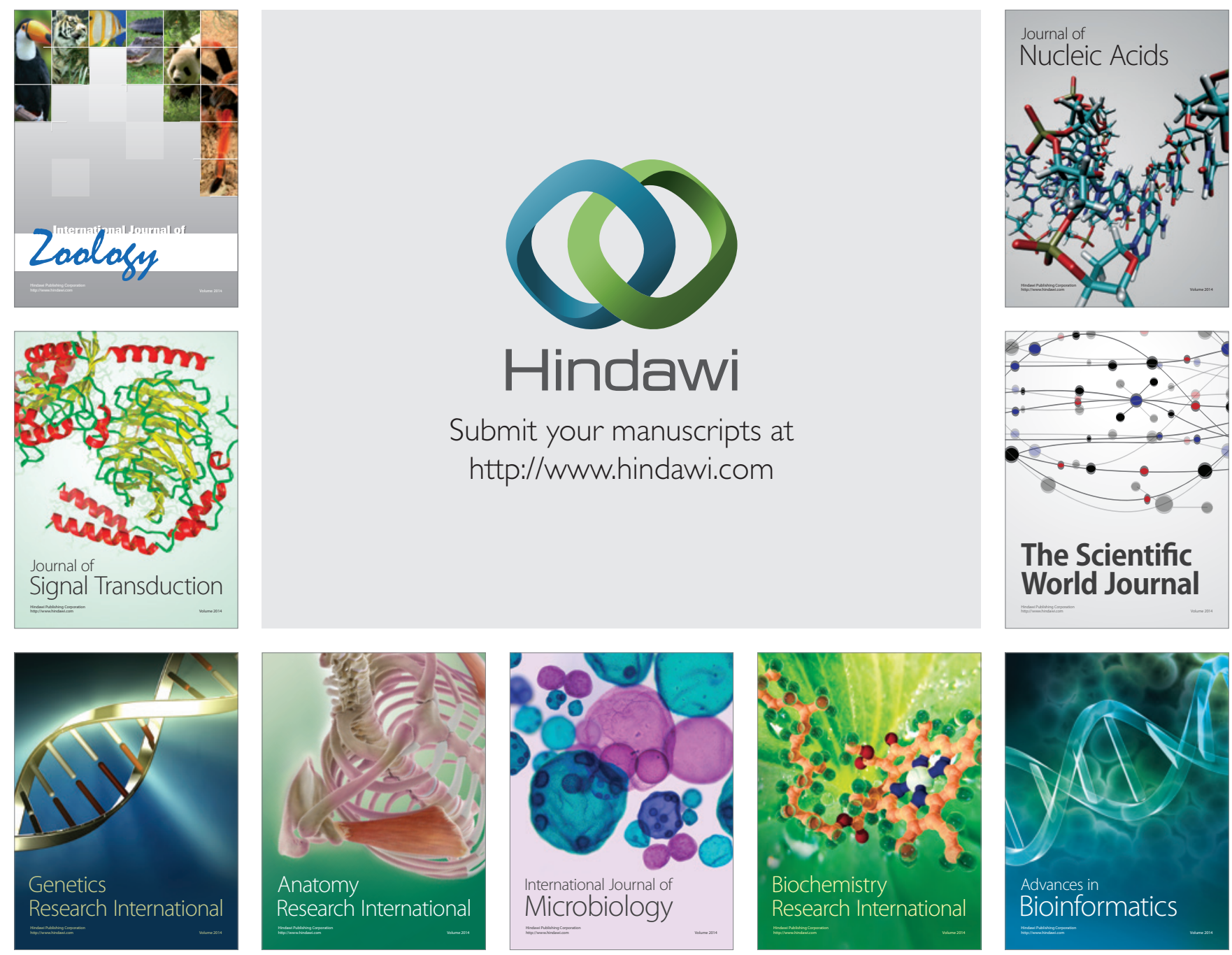

The Scientific World Journal
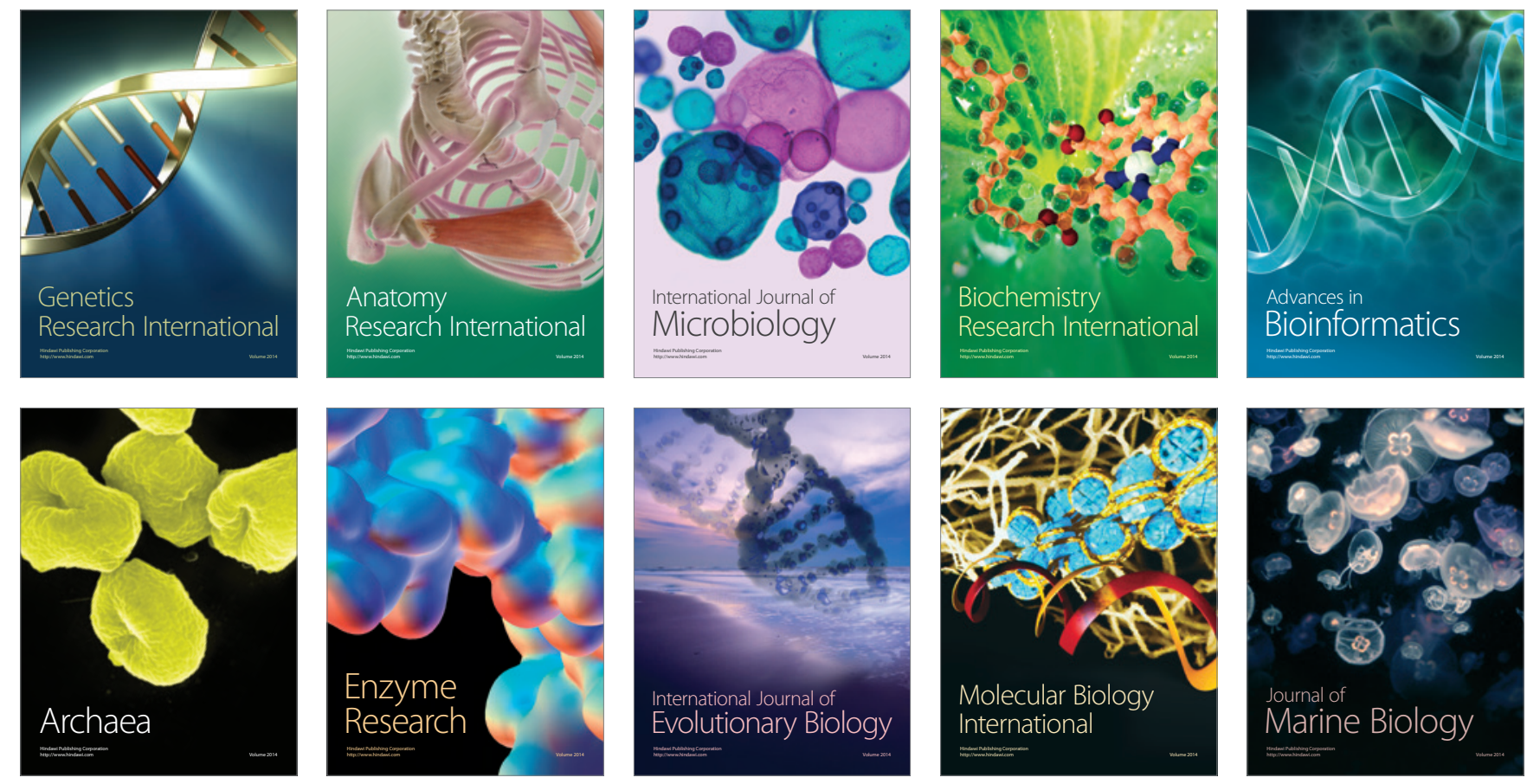